\title{
CAMPOS E FLORESTAS NO CURSO MÉDIO DO RIO TOROPI, RIO GRANDE DO SUL (BRASIL). RETRATO DE UM ADMIRÁ VEL PATRIMÔNIO AMEAÇADO ${ }^{1}$
}

\author{
JOSÉ NEWTON CARDOSO MARCHIORI ${ }^{2}$ THAIS SCOTTI DO CANTO-DOROW 3 \\ HENRIQUE MALLMANN BÜNEKER ${ }^{4}$ LILIANA ESSI $^{5}$ TIAGO BÖER BREIER ${ }^{6}$ \\ RODRIGO CORREAA PONTES ${ }^{7}$
}

\begin{abstract}
RESUMO
É analisada a vegetação campestre e florestal na região do curso médio do rio Toropi, no centro do estado do Rio Grande do Sul, confirmando-se a existência de diversas espécies endêmicas, raras e/ou ameaçadas de extinção. Dada a importância desse patrimônio florístico e natural, conclui-se que a construção das centrais hidrelétricas previstas exige a criação de uma unidade de conservação para preservar os ecossistemas remanescentes.

Palavras-chave: Brasil, Butia witeckii, espécies endêmicas, Dyckia selloa, Dyckia strehliana, Echinopsis oxygona, Oxalis subvillosa, palmar, Parodia glaucina, Parodia horstii, Parodia linkii, Parodia magnifica, Parodia oxycostata, Paspalum rawitscheri, Picramnia parvifolia, Rio Grande do Sul, rio Toropi, rio Guassupi, salto do Guassupi, Tillandsia toropiensis, Trithrinax brasiliensis.
\end{abstract}

\section{ABSTRACT}

[Grasslands and forests in the middle course of Toropi River, Rio Grande do Sul State (Brazil). Portrait of a striking threatened heritage].

Forest and grassland vegetations in the middle course of Toropi River in central Rio Grande do Sul State (Brazil) are investigated, confirming the existence of many endemic, rare and/or endangered species. Given the importance of this floristic and natural heritage, it is concluded that the construction of hydroelectric dams in the region demands the creation of a conservation area to preserve the remaining ecosystems.

Keywords: Brazil, Butia witeckii, Dyckia selloa, Dyckia strehliana, Echinopsis oxygona, endemic species, Guassupi Falls, Guassupi River, Oxalis subvillosa, palm grove, Parodia glaucina, Parodia horstii, Parodia linkii, Parodia magnifica, Parodia oxycostata, Paspalum rawitscheri, Picramnia parvifolia, Rio Grande do Sul State, Toropi River, Tillandsia toropiensis, Trithrinax brasiliensis.

\section{INTRODUÇÃO}

O projeto da instalação de pequenas centrais hidrelétricas na região do curso médio do rio Toropi, próximo à foz de seu tributário Guas-

1 Recebido em 30-5-2014 e aceito para publicação em 25-6-2014.

2 Engenheiro Florestal, Dr. Professor do Departamento de Ciências Florestais, Universidade Federal de Santa Maria. Bolsista de Produtividade em Pesquisa (CNPqBrasil).marchiori@pq.cnpq.br

3 Bióloga, Dra. Professora do Departamento de Biologia, Universidade Federal de Santa Maria, RS, Brasil. thaisdorow@gmail.com

4 Acadêmico dos cursos Técnico em Paisagismo e Engenharia Florestal, Universidade Federal de Santa Maria. henrique.mb@hotmail.com supi, tem recebido escassa divulgação na sociedade gaúcha. Nesse estado de desinformação, não é de se estranhar que tais obras de engenharia sejam vistas como promissoras ao desenvolvimento regional por amplos setores da população, sobretudo em tempos de reconhecida carência no suprimento de energia elétrica.

\footnotetext{
5 Bióloga, Dra. Professora do Departamento de Biologia, Universidade Federal de Santa Maria. lili.essi@gmail.com

6 Biólogo, Dr.Professor do Departamento de Silvicultura, Instituto de Florestas, Universidade Federal Rural do Rio de Janeiro. tiagobreier@gmail.com

7 Técnico em Paisagismo e acadêmico do curso de Geografia Bacharelado, Universidade Federal de Santa Maria.rodrigocorreapontes@gmail.com
} 
Situado em região de difícil acesso, nos confins dos municípios de São Martinho da Serra, Quevedos e Júlio de Castilhos, poucos são os gaúchos que conhecem in loco o palco das obras projetadas e, portanto, se encontram habilitados para opinar, com algum fundamento, sobre o patrimônio ameaçado. A própria comunidade científica ainda não investigou adequadamente a região, cabendo salientar, entretanto, que o conhecimento disponível permite afirmar que se trata de um dos pólos de diversidade florística mais notáveis no centro-oeste do Rio Grande do Sul, e verdadeiro refúgio de inúmeras espécies endêmicas, raras e/ou ameaçadas de extinção.

Além dessas comprovadas raridades botânicas, a região em foco dispõe, no palmar de Butia witeckii e Trithrinax brasiliensis, bem como no salto do Guassupi, de dois patrimônios naturais de indiscutível importância regional, e que também exigem proteção. Ao enfocar a questão ambiental, o presente trabalho visa a divulgar aspectos praticamente desconhecidos do grande público, na expectativa de que, com melhor conhecimento, a sociedade possa avaliar o que realmente está em jogo e, no caso do andamento do projeto, buscar formas de compatibilizar, com o mínimo de riscos e danos ambientais, a preservação dos patrimônios envolvidos.

Composta de vegetações campestres e florestais, ambas as tipologias são examinadas separadamente, dado o "hiato sistemático" existente entre as mesmas. A lista de espécies e famílias botânicas é apresentada no Quadro 1, e segue a nomenclatura recomendada pelo IPNI - The International Plant Names Index.

\section{VEGETAÇÃO CAMPESTRE}

Os campos do curso médio do rio Toropi se notabilizam pela existência de um palmar ainda bem conservado e de extraordinária singularidade (Figura 1A), uma vez que é a única região de ocorrência de Butia witeckii (Figura 1B, C), espécie recentemente descrita (Soares \& Longhi, 2011), e a última área com população expressiva de Trithrinax brasiliensis (Figura 1B,
D), uma das palmeiras mais ameaçadas de extinção no sul do Brasil, de acordo com Soares et al. (2014).

A respeito desses campos, cabe salientar que além de seu indiscutível caráter de patrimônio natural, conferido por ambas as palmeiras, a vegetação também inclui árvores isoladas, agrupamentos de espécies lenhosas e pequenos capões-de-mato, bem como diversas espécies raras, endêmicas e/ou ameaçadas de extinção, sobretudo no diversificado estrato herbáceo, em lajedos e escarpas rochosas.

No palmar, o estrato arbustivo-herbáceo é marcado, tanto em sua fisionomia como estrutura, por hemicriptófitas, caméfitas e nanofanerófitas, salientando-se as gramíneas Paspalum notatum, Paspalum plicatulum e as conhecidas barbas-de-bode (Aristida jubata, Aristida venustula, Aristida filifolia), uma espécie de caraguatá (Eryngium horridum), duas guavirovas-do-campo (Campomanesia hatschbachii, Campomanesia aurea), além do quitoco (Pterocaulon polystachyum), uma espécie de carqueja (Baccharis crispa), e o barbasco (Buddleja thyrsoides).

Apesar de pouco conspícuas na estrutura da vegetação - e menos freqüentes no espaço regional -, a flora herbácea ainda inclui diversas Asteráceas dignas de nota (Gamochaeta americana, Stenachaenium campestre, Trixis pallens), bem como Acantáceas (Carlowrightia sulcata, Ruellia brevicaulis), Asclepiadáceas (Oxypetalum coccineum), Convolvuláceas ( $D i$ chondra sericea), Fabáceas (Pomaria rubicunda (Figura 2C), Desmodium cuneatum), Poáceas (Paspalum rawistscheri), e Solanáceas (Nierembergia pinifolia), entre outras famílias botânicas. No caso de Paspalum rawitscheri (Figura 2A, B), espécie endêmica do sul do Brasil, cabe salientar que essa gramínea raramente é encontrada na natureza (Rua \& Valls, 2012) e foi incluída na lista de espécies ameaçadas da flora brasileira como "vulnerável" (Boldrini, 2009), devido à redução progressiva dos já "escassos indivíduos sobreviventes em populações conhecidas" (Valls et al., 2009). 

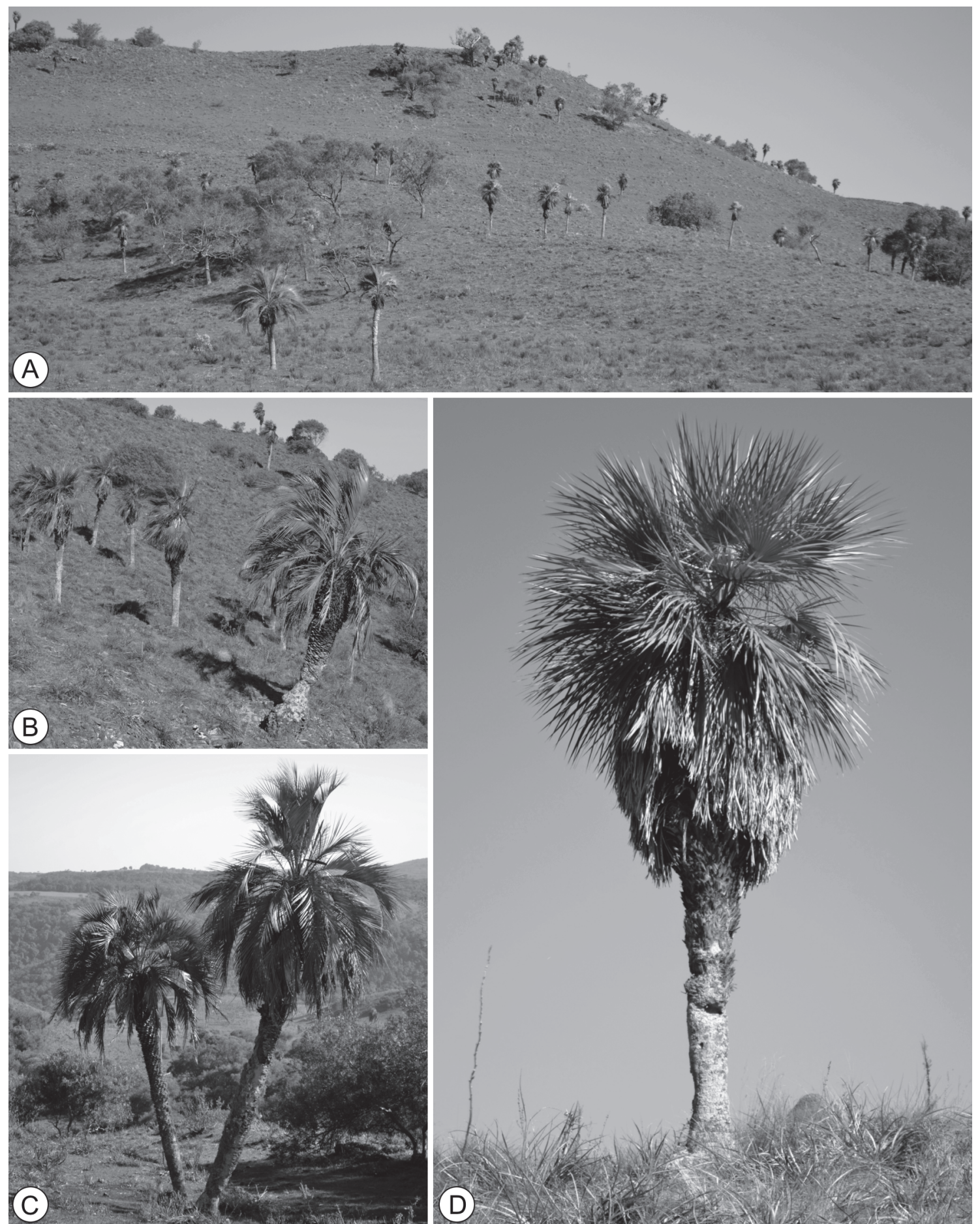

(C)

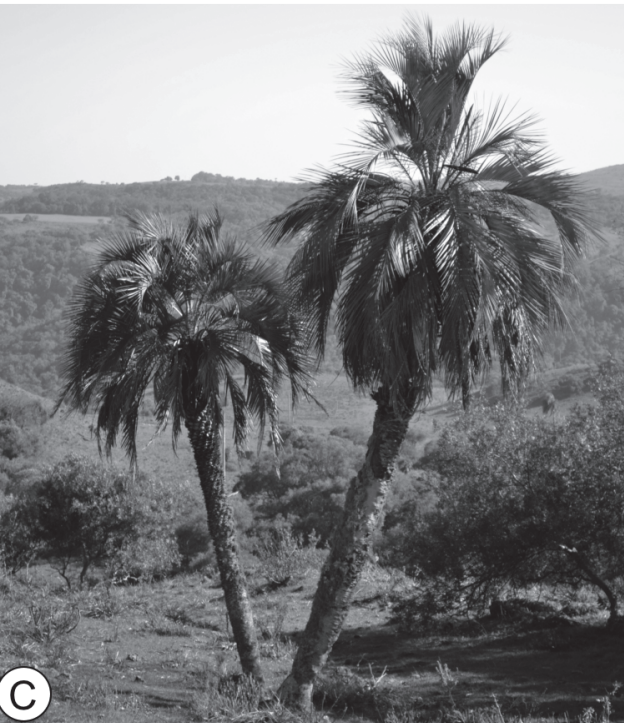

FIGURA 1 - Palmar do Quebra-Dentes. A - Vista geral. B - Indivíduos de Butia witeckii e Trithrinax brasiliensis. C - Butia witeckii. D - Trithrinax brasiliensis. 

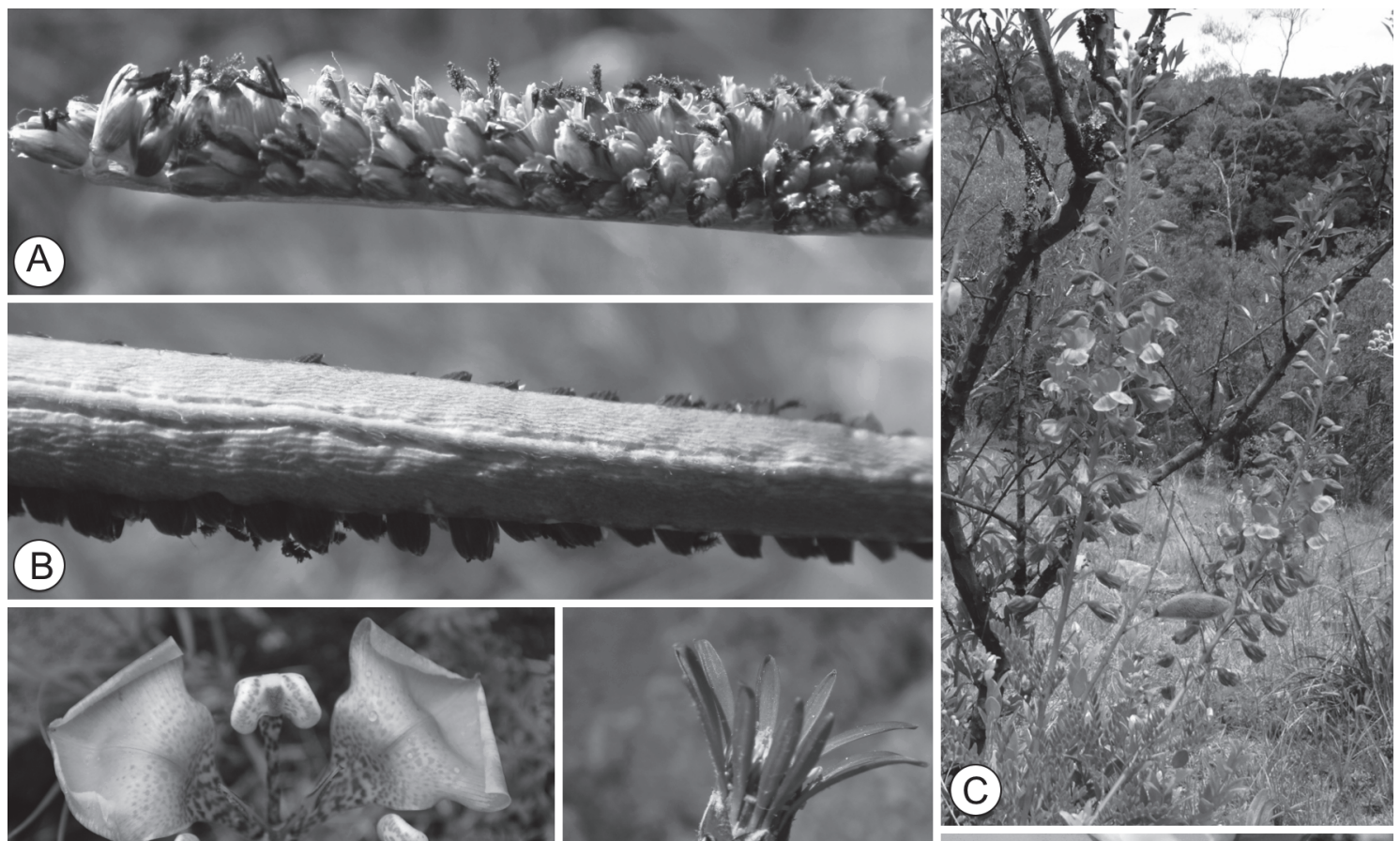

(B)
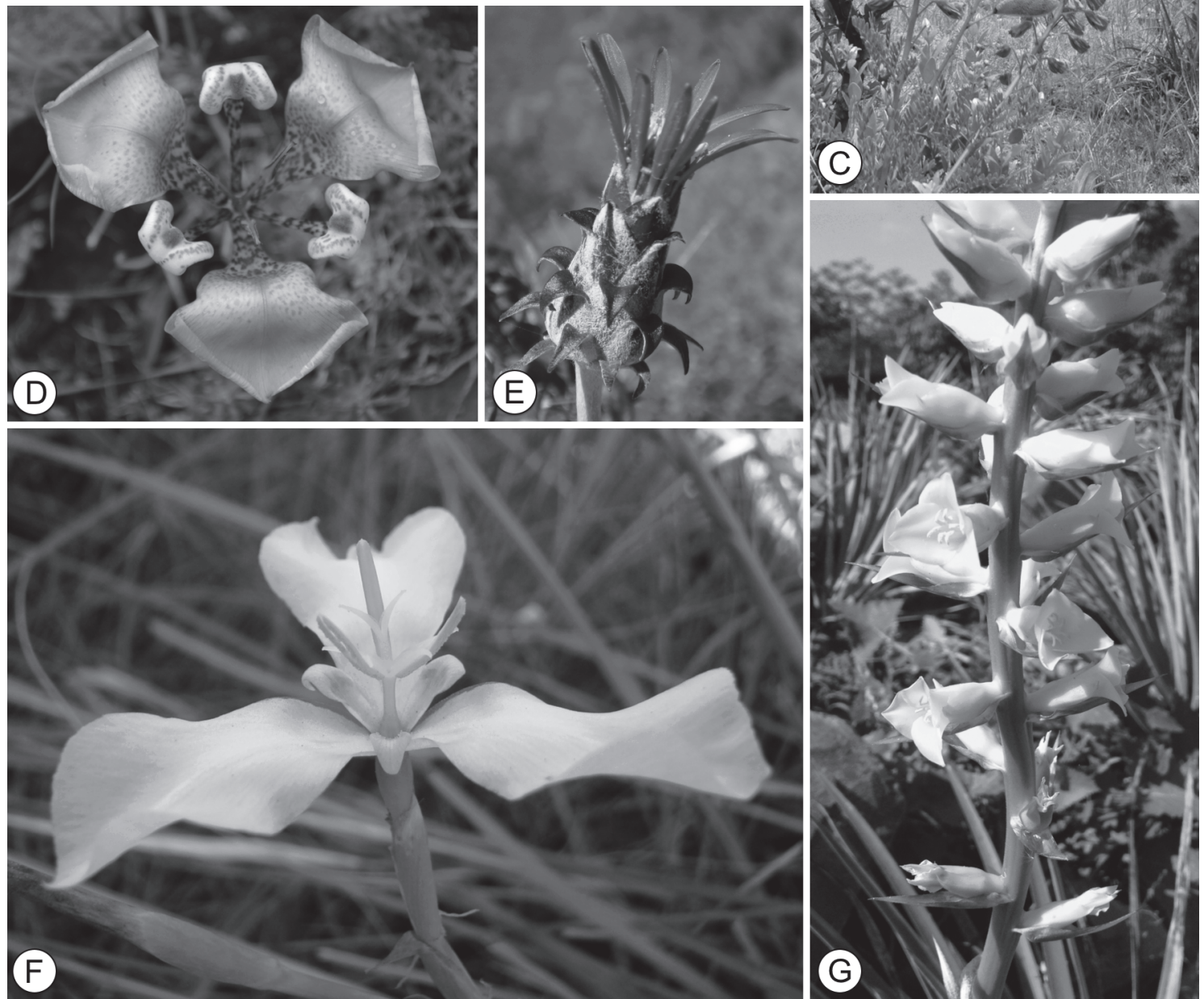

FIGURA 2 - Flora campestre. A - Vista da porção adaxial da inflorescência de Paspalum rawitscheri. B - Vista da porção abaxial de Paspalum rawitscheri. C - Inflorescência de Pomaria rubicunda (Foto de Leopoldo Witeck Neto). D - Visão superior da flor de Onyra unguiculata. E - Vista lateral do capítulo de Mutisia coccinea. F - Vista lateral da flor de Herbertia amabilis (Foto de Leonardo Paz Deble). G - Detalhe da inflorescência de Dyckia ibicuiensis. 
Das microfanerófitas, que crescem isoladamente ou integram agrupamentos de arvoretas e pequenos capões-de-mato, salientam-se: a aroeira-brava (Lithraea molleoides), a aroeiracinzenta (Schinus lentiscifolius), o pinheiro-bravo (Podocarpus lambertii), a viuvinha (Chomelia obtusa), o veludinho (Guettarda uruguensis), a poaia (Machaonia brasiliensis), a coronilha (Scutia buxifolia), o esporão-de-galo (Strychnos brasiliensis), o tarumã (Vitex megapotamica), a mamica-de-cadela (Zanthoxylum rhoifolium), o branquilho (Sebastiania commersoniana), a cancorosa (Maytenus muelleri), o ariticum (Annona emarginata), a sete-sangrias (Symplocos uniflora), o cocão (Erythroxylum argentinum), a pitangueira (Eugenia uniflora), a unha-de-gato (Senegalia tucumanensis), o pau-amargo (Picramnia parvifolia) e a tuna (Cereus hildmannianus).

Em meio a cornijas, no alto ou à meia-encosta de colinas, indivíduos isolados de uma Ericácea se impõem na paisagem: trata-se da criúva (Agarista eucalyptoides), espécie que, apesar da escassa frequiência, apresenta ampla dispersão no sul do Brasil.

Das lianas, destacam-se Janusia guaranitica (Malpighiaceae) e dois cravos-divinos: Mutisia coccinia (Figura 2E) e Mutisia speciosa (Asteraceae).

$\mathrm{Na}$ orla da mata ciliar, a abundância de goiabas-do-campo (Acca sellowiana, Figura 5E), aroeiras-piriquita (Schinus molle) e guamirinsfacho (Calypthranthes concinna) chegam a conferir uma fisionomia de savana em muitos locais.

Do numeroso contingente de geófitas, destacam-se as Iridáceas Onira unguiculata (Figura 2D), em sítios litólicos, e Herbertia amabilis (Figura 2F), em solos mais profundos e argilosos, cabendo salientar que a última foi recentemente descrita para o município de Júlio de Castilhos, constituindo notório endemismo. Outra espécie que se enquadra nesta categoria é Dyckia ibicuiensis (Figura 2G), bromeliácea com distribuição restrita a solos litólicos da região central do Rio Grande do Sul, e que inte- gra a lista nacional (e do Rio Grande do Sul) de espécies ameaçadas de extinção.

Nas escarpas rochosas situadas à margem dos rios Toropi e Guassupi, bem como no próprio lajedo desses cursos de água, o expressivo contingente de Cactáceas, Bromeliáceas e Iridáceas raras e/ou endêmicas ali encontradas, demonstra que se trata de áreas prioritárias de conservação e que, como tal, precisam ser reconhecidas pelo poder público, a quem cabe a iniciativa de medidas legais de proteção. É essa singular comunidade de plantas reófilas e saxícolas (Figuras 3A, 4A) que mais se encontra ameaçada pelas pequenas centrais hidreléticas $(\mathrm{PCH})$ a serem construídas nos rios Guassupi e Toropi, uma vez que seus nichos ecológicos são os mais diretamente afetados pela formação dos lagos, juntamente com a mata ciliar adjacente (Figura 6A). Na lista de espécies ameaçadas salientamse Echinopsis oxygona (Figura 3B), Opuntia elata (Figura 4D), Parodia glaucina, Parodia horstii (Figura 4B), Parodia linkii, Parodia magnifica (Figura 4C), Parodia ottonis e Parodia oxycostata, da família Cactaceae (Anderson, 2001; Hofacker, 2013; Ritter, 1979), bem como a Iridácea Trimezia spathata, e três Bromeliáceas: Dyckia selloa (Figura 3B), Dyckia strehliana (Figura 3D, E) e Tillandsia toropiensis (Figura 4D).

A respeito de Tillandsia toropiensis, cabe salientar que a espécie tem distribuição restrita às escarpas rochosas das margens do rio Toropi e de seu tributário Guassupi, sendo que o holótipo foi originalmente coletado na década de 1970 por Werner Rauh, famoso especialista alemão em Bromeliáceas, nas proximidades da casa de máquinas da antiga Usina Hidrelétrica de Quebra-Dentes (Rauh, 1984).

Dyckia strehliana, por sua vez, é reófita descrita recentemente (Büneker et al., 2013) e conhecida apenas para a localidade típica, nos lajedos (Figura 3D, E) da região de QuebraDentes.

A respeito das espécies reófilas do gênero Dyckia, cabe ressaltar que as mesmas têm distribuição restrita a esse tipo de ambiente, moti- 

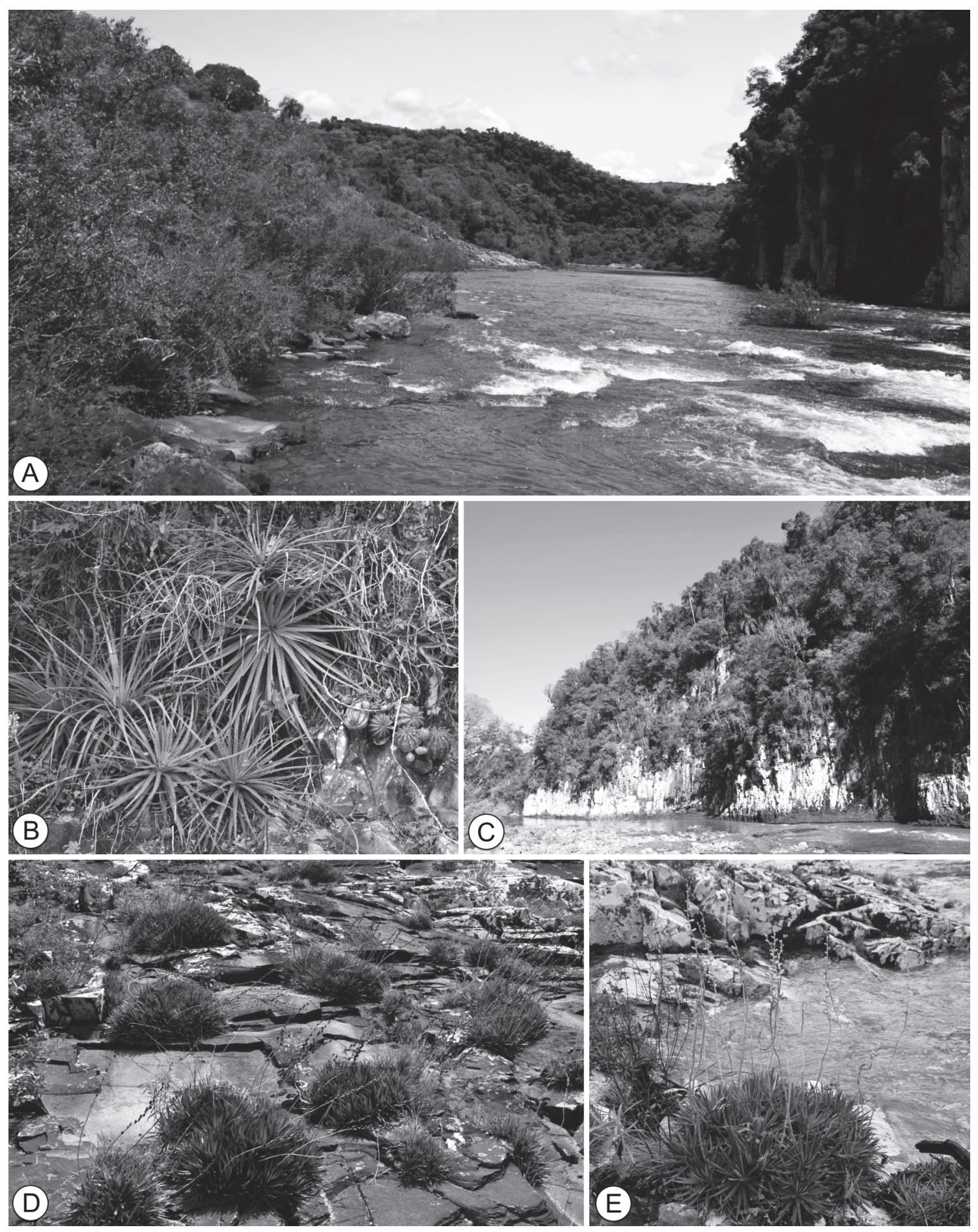

FIGURA 3 - Margens do rio Toropi. A - Rio Toropi e o ambiente ciliar. B - Dyckia selloa e Echinopsis oxygona. $\mathrm{C}$ - Escarpa rochosa às margens do rio Toropi. D - Lajedos as margens do rio Toropi, com a presença da reófita Dyckia strehliana. E - Touceira hemisférica de Dyckia strehliana, as margens do rio Toropi. 

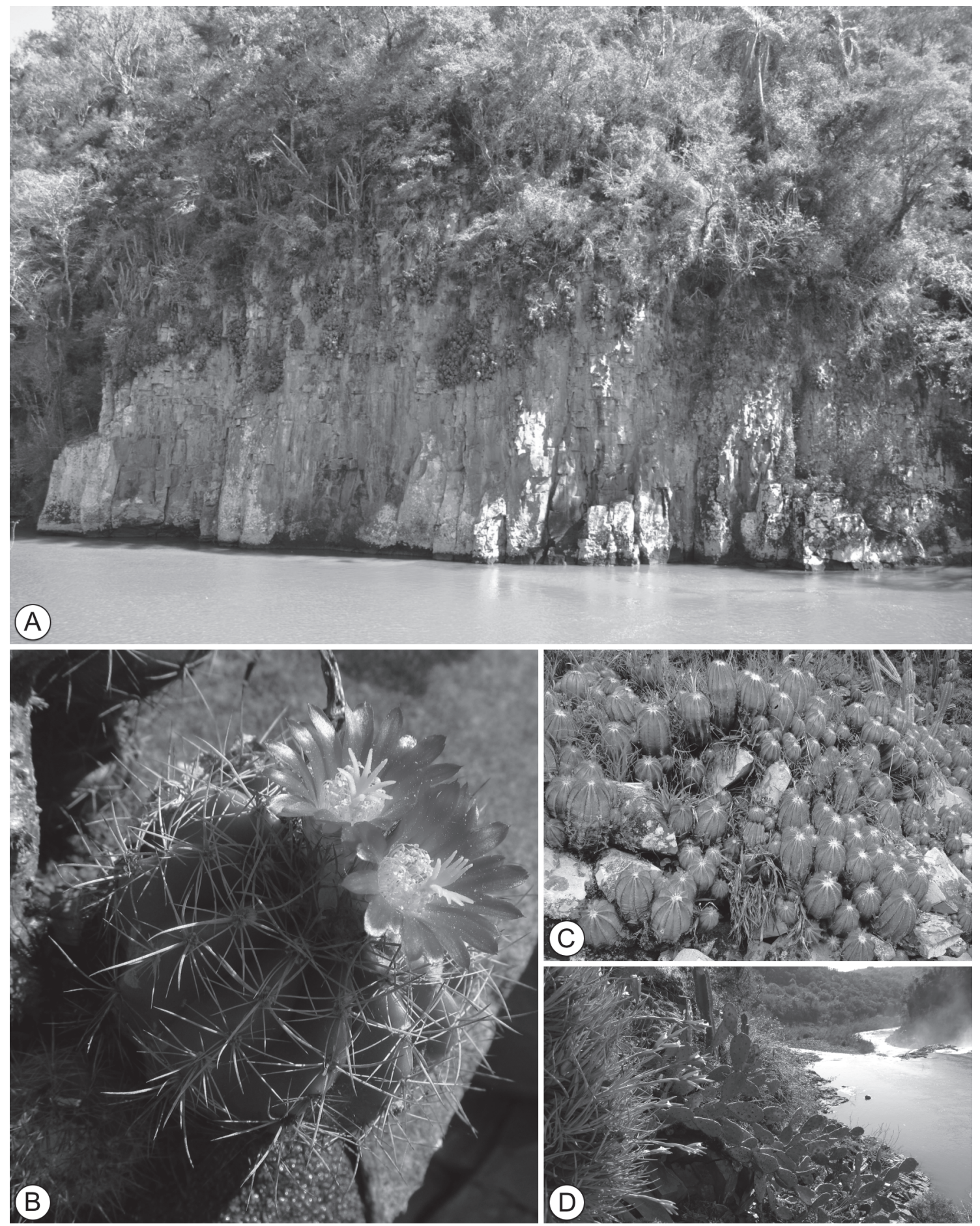

FIGURA 4 - Espécies das escarpas rochosas localizadas às margens dos rios Toropi e Guassupi. A - Aspecto de uma escarpa rochosa, hábitat de Parodia magnifica e Tillandsia toropiensis. B - Hábito de Parodia horstii. C - Vista de parte da população de Parodia magnifica. D - Tillandsia toropiensis, à esquerda; Opuntia elata, ao centro. 
vo pelo qual são plantas severamente ameaçadas de extinção e suas populações, reduzidas pela construção de represas, constituem motivo de grande preocupação para ambientalistas e órgãos governamentais. O caso de Dyckia distachya tornou-se bem conhecido pela ampla divulgação recebida nos últimos anos: espécie endêmica das margens rochosas do rio Uruguai, no limite entre os estados de Santa Catarina e Rio Grande do Sul, suas populações naturais acabaram afogadas pelos lagos das usinas hidrelétricas de Itá, Machadinho e Barra Grande (Prochnow, 2005; Wiesbauer, 2008; Wiesbauer et al., 2009).

\section{VEGETAÇÃO FLORESTAL}

A composição das matas ciliares (Figura 6A) no curso médio do rio Toropi e afluentes dispõe, em Figueiredo (2014), de uma referência bibliográfica consistente, haja vista o criterioso levantamento dos estratos arbustivo-arbóreo e herbáceo, realizado em 19 transectos.

De início, cabe ressaltar que a relativa pobreza em espécies endêmicas, raras e/ou ameaçadas de extinção é aspecto bem conhecido nas formações florestais do estado, em nítido contraste com o observado em formações abertas. De difícil percepção popular, devido à fisionomia luxuriante sugerida pela complexa estrutura vertical das florestas, este aparente paradoxo se explica pela imigração recente de grande parte das espécies arbóreas no espaço regional, com exceção dos elementos extratropicais, remanescentes dos fragmentos pleistocênicos. Nas florestas sul-rio-grandenses, por consequiência, as raridades florísticas usualmente se encontram nas sinúsias epifítica, herbácea e de lianas, sendo raras as espécies endêmicas no componente lenhoso ou arbóreo.

A respeito das árvores, foram identificadas 47 espécies, distribuídas em 24 famílias botânicas, destacando-se Myrtaceae, Fabaceae e Rutaceae, com 9, 5 e 4 espécies, respectivamente. O pinho-bravo (Podocarpus lambertii), espécie com maior número de indi- víduos amostrados, também apresentou os maiores valores de freqüência absoluta e relativa.

Um dos pontos que chama atenção é a escassa diversidade de espécies reófilas lenhosas (Figura 3A). Representado, tão somente, pelo amarilho (Terminalia australis) e pelo topetede-cardeal (Calliandra tweediei, Figura 5F), esse grupo de plantas contrasta, vivamente, com o observado em trechos de mata ciliar do próprio rio Toropi em seu curso final, na região fisiográfica da Depressão Periférica, fato que pode ser atribuído à acidentada geomorfologia da região, evidenciada, aliás, pelas escarpas anteriormente comentadas e pelas corredeiras dos rios Toropi e Guassupi, aspectos desfavoráveis à gênese de trechos aluviais de floresta.

$\mathrm{Na}$ florística da mata ciliar se evidenciam, claramente, os vínculos com vegetações de outras regiões do estado, mesmo em rápido exame do componente arbóreo.

Em primeiro lugar, a vegetação da mata ciliar não esconde uma marcada contribuição de elementos extratropicais, integrantes da Floresta Mista - e não apenas pelos altos índices do pinho-bravo em sua estrutura -, como, também, pela presença de outras espécies associadas a essa tipologia, salientando-se: Quillaja brasiliensis (sabão-de-soldado), Annona rugulosa (araticum), Ilex brevicuspis (congonha), Ilex theezans (caúna), e Myrcianthes gigantea (araçá-do-mato).

Do contingente estreitamente vinculado à floresta do Alto Uruguai, destacam-se Balfourodendron riedelianum (guatambu) e Machaerium paraguariense (farinha-seca).

A grande maioria das espécies lenhosas apresenta ampla dispersão nas formações silváticas do estado, bem como destacada presença na Floresta Estacional Decídua do rebordo do Planalto Meridional, salientando-se, pelo grande porte dos indivíduos: a guajuvira (Cordia americana), o angico-vermelho (Parapiptadenia rigida), o açoita-cavalo (Luehea divaricata), o camboatá-vermelho (Cupania vernalis), a murta (Blepharocalyx salicifolius), o guabiju 

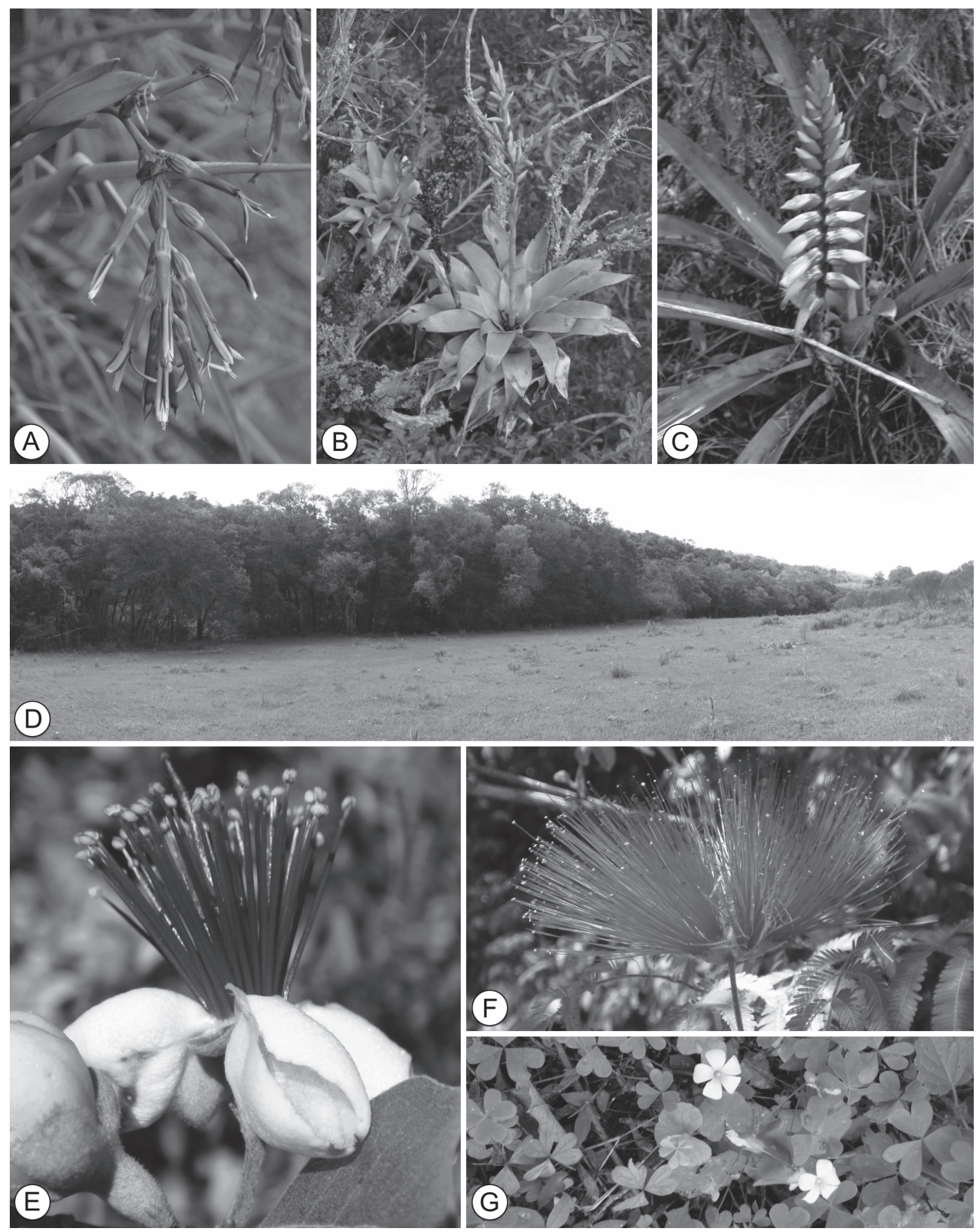

FIGURA 5 - Vegetação florestal. A - Detalhe da inflorescência de Billbergia nutans. B - Aspecto geral de Vriesea friburguensis. C - Detalhe da inflorescência de Vriesea platynema. D - Aspecto da borda da mata (Foto de Maria Carolina dos Santos Figueiredo). E - Flor de Acca sellowiana. F - Inflorescência de Calliandra tweediei (Foto de Maria Carolina dos Santos Figueiredo). G - Oxalis subvillosa (Foto de Maria Carolina dos Santos Figueiredo). 
(Myrcianthes pungens), a canela-preta (Nectandra megapotamica), e a canela-lageana (Ocotea pulchella). Embora de menor porte, também participam do dossel, sobretudo em áreas de estrutura vertical menos desenvolvida: a canela-de-veado (Helietta apiculata), o branquilho (Sebastiania commersoniana), o leiteiro (Sebastiania brasiliensis), a carne-de-vaca (Styrax leprosus), a sete-sangrias (Symplocos uniflora), o chal-chal (Allophylus edulis), além de algumas Mirtáceas (Campomanesia xanthocarpa, Eugenia involucrata, Eugenia uruguayensis, Eugenia uniflora).

No sub-bosque, o estrato das arvoretas baseia-se em poucas espécies, comparado a outras regiões do estado, reunindo, basicamente: a laranjeira-do-mato (Actinostemon concolor), o pau-de-ervilha (Trichilia elegans), o manacá (Brunfelsia australis) e a embira (Daphnopsis racemosa).

$\mathrm{Na}$ sinúsia das epífitas destacam-se as bromeliáceas Billbergia nutans (Figura 5A) Vriesea friburgensis (Figura 5B) e Vriesea platynema (Figura 5C), sendo que a última, de ocorrência rara no interior do continente, tem no curso médio do rio Toropi o seu provável limite ocidental no Rio Grande do Sul.

Na orla da mata ciliar, adjacente ao campo (Figura 5D), predominam espécies típicas da bordadura, tais como a crindiuva (Trema micrantha) e a pixirica (Miconia hyemalis), juntamente com arvoretas anteriormente citadas para os capões, tais como a aroeira-brava (Lithraea molleoides), a viuvinha (Chomelia obtusa) e o carvalhinho (Casearia sylvestris). Resta acrescentar que a taquara-de-espinho (Guadua trinii) é espécie nativa na vegetação em estudo, à semelhança do observado em outras matas ciliares, tanto no Planalto Médio como na Depressão Periférica.

Para o estrato herbáceo, Figueiredo (2014) identificou 28 espécies, de 16 famílias botânicas, salientando-se Asteraceae e Poaceae, com cinco espécies cada uma. Todos os binômios listados são de espécies nativas, sendo que três delas integram a lista da flora ameaçada do Rio
Grande do Sul, de acordo com o Decreto Estadual n. 42.099, de 01/01/2003: Chamissoa acuminata e Pfaffia glomerata (Amaranthaceae), e Smallanthus connatus (Asteraceae). Por sua vez, o registro de Oxalis subvillosa (Oxalidaceae, Figura 5G) no talude à beira do rio Guassupi, no interior da mata ciliar, reforça a lista de raridades botânicas da flora regional, por ser a primeira citação dessa espécie no Rio Grande do Sul.

Por fim, cabe salientar que a mata ciliar apresenta largura muito variável no curso médio dos rios Toropi e Guassupi, chegando, não raro, a desaparecer por completo no alto de escarpas adjacentes aos cursos de água, demonstrando a influência de fatores edáficos na tipologia.

\section{CONSIDERAÇÕES FINAIS}

Situada nos confins dos municípios de Júlio de Castilhos, São Martinho da Serra e Quevedos, a região do curso médio do rio Toropi distingue-se por sua notável diversidade florística e elevado número de espécies endêmicas, raras e/ou ameaçadas de extinção, motivo suficiente para que a mesma seja reconhecida, pela comunidade e poder público, como área prioritária para fins de conservação. Além dos efeitos práticos decorrentes desse reconhecimento, o que cabe analisar, de início, são os motivos que justificam essa singularidade no espaço regional.

A despeito de tratar-se de área ainda subcoletada, de acordo com registros de herbário, e da escassa bibliografia disponível, não há como desconhecer que a região em foco é um dos locais de diversidade florística mais importantes no centro do Rio Grande do Sul. A explicação para o fato deve ser buscada em diversas fontes.

Sob o ponto de vista geomorfológico, o relevo, dissecado pelo curso dos rios Guassupi e Toropi, proporciona nichos ecológicos muito distintos no tocante ao material de origem, declividade, tipo e profundidade de solos, exposição, luminosidade e disponibilidade hídrica, com reflexos positivos para a diversidade florística. 


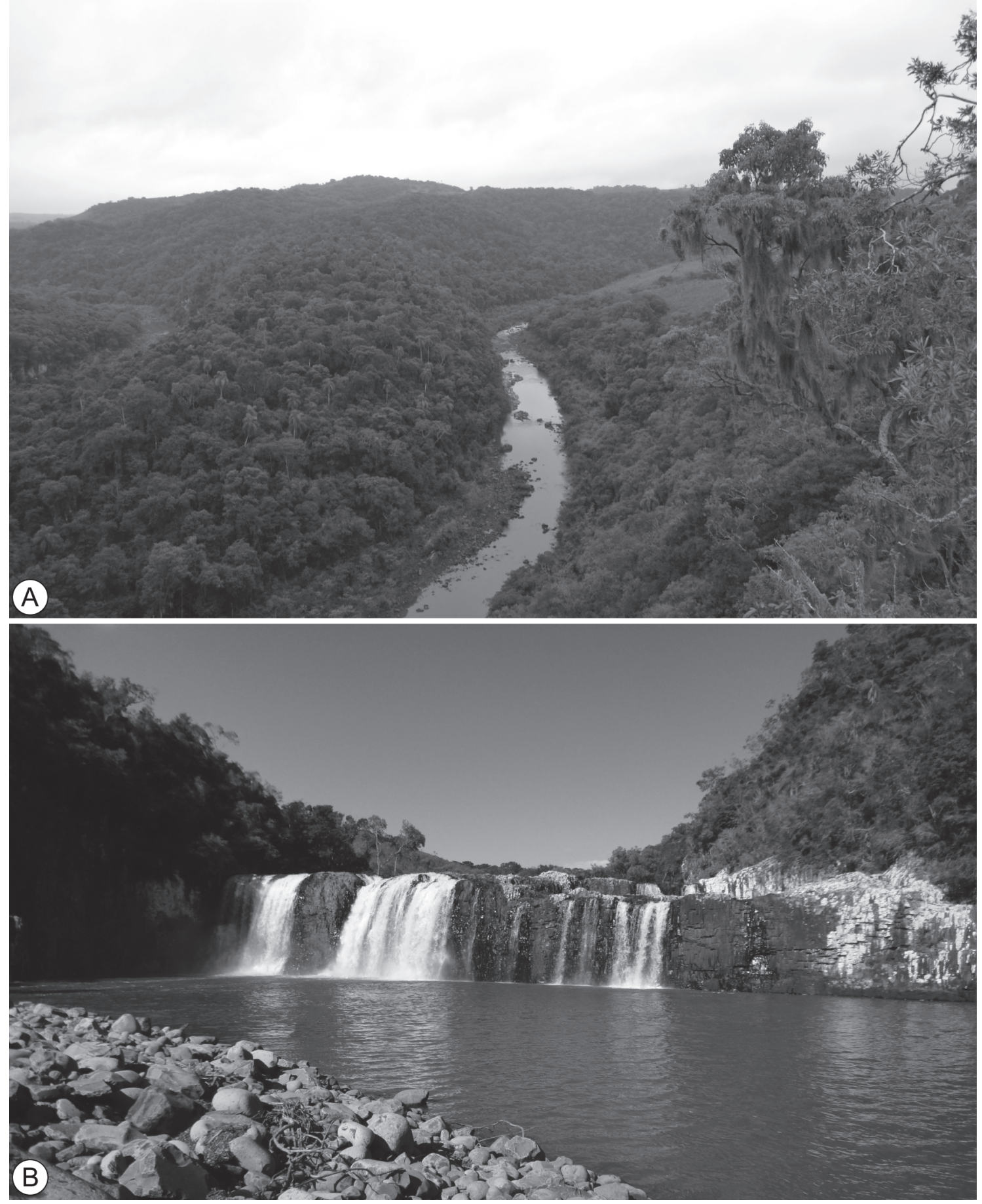

FIGURA 6 - Dois patrimônios naturais. A - Aspecto geral do rio Guassupi, margeado pela floresta. B - Vista geral do Salto do Guassupi. 
A análise da vegetação, por sua vez, não esconde um marcado caráter de ecótono, posto que congrega elementos Pampeano-Chaquenhos, amplamente dominantes na zona campestre, a um diversificado contingente oriundo do Bioma Mata Atlântica, seja da Floresta Estacional Decidual ou das florestas ombrófilas Mista e Atlântica propriamente dita.

O posicionamento geográfico, nos confins de três municípios, juntamente com o difícil acesso à rede de estradas, o relevo movimentado e o solo pouco favorável à mecanização (afloramento de rochas), são fatores historicamente desfavoráveis ao avanço da agricultura em larga escala, atividade que, em outros pontos, levou a uma transformação radical da paisagem, mediante a expansão de cultivos em áreas outrora ocupadas por campos naturais. Por sua vez, a pecuária extensiva, atividade econômica tradicional da região, é bem conhecida por seu impacto menor para a biodiversidade, salientando-se, todavia, o efeito prejudicial de eventuais queimadas e o exercido pelo gado sobre o recrutamento de jovens palmeiras, devido à predação de brotações.

A riqueza de endemismos e raridades botânicas existente na região de Quebra-Dentes constitui desafio técnico-ambiental que precisa ser equacionado a contento, antes de se comprometer esse inestimável patrimônio com as obras de engenharia previstas. Cabe salientar, no entanto, que além das preciosidades florísticas anteriormente assinaladas, também se encontram na região dois patrimônios naturais de primeira grandeza, e que exigem preservação, para o bem das futuras gerações: o palmar de butiás e buritis, anteriormente abordado, e o salto do rio Guassupi (Figura 6B), foco turístico ainda pouco conhecido pela dificuldade de acesso.

A construção das projetadas usinas hidrelé- tricas causa grande preocupação na comunidade científica - e não apenas pela perda ou prejuízo a esses patrimônios naturais e florísticos -, mas, inclusive, pela eventual adoção de medidas compensatórias equivocadas de impacto ambiental, tais como a previsão de plantios de árvores em faixa marginal aos lagos. Em vez de medida mitigadora, a adoção dessa prática se mostra especialmente nociva na região do Quebra Dentes, uma vez que, pelo afogamento da mata ciliar, os espelhos de água a serem formados pelas barragens vão estar em contato direto com a vegetação campestre, a qual é tão (ou mais) valiosa, sob os pontos de vista ambiental, florístico e de patrimônio natural, do que os trechos mais representativos da mata nativa.

Dada a natural fragilidade dos ecossistemas, outra diretriz a ser lembrada na região do Quebra Dentes é que (re) florestamentos de qualquer natureza são fortemente contraindicados, em princípio, e não se justificam ambientalmente, devido aos conhecidos riscos da introdução de espécies em sítios pedregosos e de relevo movimentado. No caso da construção das usinas hidrelétricas previstas, a criação de uma unidade de conservação na região do QuebraDentes se mostra indispensável como medida mitigadora de impacto ambiental, com vistas à preservar os ecossistemas remanescentes.

Por compromisso intelectual, a academia não pode ficar alheia às questões trazidas a debate pelas projetadas centrais hidreléticas do rio Toropi. É pelos patrimônios natural, ambiental e florístico postos em jogo, e tendo em vista a responsabilidade social que a cidadania espera da comunidade científica, que vimos à público esclarecer aspectos pouco divulgados da biodiversidade local, bem como afiançar, com nosso testemunho, o invulgar e frágil patrimônio ameaçado, que não admite qualquer tipo de aventuras. 
QUADRO 1 - Nomes científicos e famílias botânicas das espécies citadas.

Acca sellowiana (O.Berg) Burret

Myrtaceae

Actinostemon concolor (Spreng.) Müll.Arg. ${ }^{8}$

Euphorbiaceae

Agarista eucalyptoides (Cham. \& Schltdl.) G.Don

Ericaceae

Allophylus edulis (A.St.-Hil.) Niederl.

Sapindaceae

Annona emarginata (Schltdl.) H.Rainer ${ }^{9}$

Annonaceae

Annona rugulosa (Schltdl.) H.Rainer ${ }^{10}$

Annonaceae

Aristida jubata (Arechav.) Herter

Poaceae

Aristida venustula Arechav.

Poaceae

Baccharis crispa Spreng.

Asteraceae

Balfourodendron riedelianum (Engl.) Engl.

Rutaceae

Billbergia nutans $\mathrm{H}$. Wendl. ex Regel

Bromeliaceae

Blepharocalyx salicifolius (Kunth) O.Berg

Myrtaceae

Brunfelsia australis Benth.

Solanaceae

Buddleja thyrsoides Lam.

Buddlejaceae

Butia witeckii K.Soares \& S.Longhi

Arecaceae

Calliandra tweediei Benth.

Fabaceae

Calyptranthes concinna DC.

Myrtaceae

Campomanesia aurea O.Berg

Myrtaceae

Campomanesia hatschbachii Mattos

Myrtaceae

Campomanesia xanthocarpa O.Berg

Myrtaceae

Carlowrightia sulcata (Nees) C.Ezcurra

Acanthaceae

Casearia sylvestris $\mathrm{Sw}$

Flacourtiaceae $^{11}$

Cereus hildmannianus K.Schum.

Cactaceae

Chamissoa acuminata Mart.

Amaranthaceae

Chomelia obtusa Cham. \& Schltdl.

Rubiaceae

Cordia americana (L.) Gottschling \& J.E.Mill.

Boraginaceae

Cupania vernalis Cambess.

Sapindaceae

Daphnopsis racemosa Griseb.

Thymelaeaceae

Desmodium cuneatum Hook. \& Arn.

Fabaceae

Dichondra sericea Sw.

Convolvulaceae

Dyckia distachya Hassl.

Bromeliaceae

Dyckia ibicuiensis Strehl

Bromeliaceae

Dyckia selloa (K. Koch) Baker

Bromeliaceae

Dyckia strehliana H.Büneker \& R.Pontes

Bromeliaceae

Echinopsis oxygona (Link \& Otto) Pfeiff. \& Otto

Cactaceae

Eryngium horridum Malme

Apiaceae

Erythroxylum argentinum O.E.Schulz

Erythroxylaceae

Eugenia involucrata DC.

Myrtaceae

Eugenia uniflora $\mathrm{L}$.

Myrtaceae

Eugenia uruguayensis Cambess.

Myrtaceae

Gamochaeta americana (Mill.) Wedd

Asteraceae

8 Gymnanthes concolor Spreng., segundo Sobral \& Jarenkow (2006, p. 106).

9 Rollinia salicifolia Schltdl., segundo Sobral \& Jarenkow (2006, p. 89).

${ }^{10}$ Rollinia rugulosa Schltdl., segundo Sobral \& Jarenkow (2006, p. 89).

${ }^{11}$ Salicaceae, segundo Sobral \& Jarenkow (2006, p. 148). 
Guadua trinii (Nees) Rupr.

Poaceae

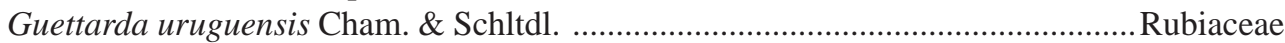

Helietta apiculata Benth.

Rutaceae

Herbertia amabilis Deble \& F.S.Alves.

Iridaceae

Ilex brevicuspis Reissek

Aquifoliaceae

Ilex theezans Mart.

Aquifoliaceae

Janusia guaranitica A.Juss.

Malpighiaceae

Lithraea molleoides (Vell.) Engl.

Anacardiaceae

Luehea divaricata Mart. \& Zucc.

Tiliaceae $^{12}$

Machaerium paraguariense Hassl.

Fabaceae

Machaonia brasiliensis Cham. \& Schltdl. ${ }^{13}$

Rubiaceae

Maytenus muelleri Schwacke

Celastraceae

Miconia hyemalis A. St.-Hil. \& Naudin ${ }^{14}$

Melastomataceae

Mutisia coccinea A.St.-Hil.

Asteraceae

Mutisia speciosa Aiton ex Hook.

Asteraceae

Myrcianthes gigantea (D.Legrand) D.Legrand

Myrtaceae

Myrcianthes pungens (O.Berg) D.Legrand

Myrtaceae

Nectandra megapotamica $\mathrm{Mez}^{15}$

Lauraceae

Nierembergia pinifolia Miers

Solanaceae

Ocotea pulchella Mart. ${ }^{16}$

Lauraceae

Onyra unguiculata (Baker) Ravenna

Iridaceae

Opuntia elata Salm-Dyck

Cactaceae

Oxalis subvillosa Norlind

Oxalidaceae

Oxypetalum coccineum Griseb.

Asclepiadaceae

Parapiptadenia rigida (Benth.) Brenan

Fabaceae

Parodia glaucina (F.Ritter) Hofacker \& Machado

Cactaceae

Parodia horstii (F.Ritter) N.P.Taylor

Cactaceae

Parodia linkii (Lehmann) Kiesling

Cactaceae

Parodia magnifica (F.Ritter) F.H.Brandt

Cactaceae

Parodia ottonis (Lehmann) N.P.Taylor

Cactaceae

Parodia oxycostata (Buining \& Brederoo) Hofacker.

Cactaceae

Paspalum notatum Flüggé

Poaceae

Paspalum plicatulum Michx.

Poaceae

Pfaffia glomerata (Spreng.) Pedersen

Amaranthaceae

Picramnia parvifolia Engl.

Simaroubaceae

Podocarpus lambertii Klotzsch ex Endl.

Podocarpaceae

Pomaria rubicunda (Vogel) B.B.Simpson \& G.P.Lewis

Fabaceae

Quillaja brasiliensis Mart.

Rosaceae $^{17}$

Pterocaulon polystachyum DC.

Asteraceae

Ruellia brevicaulis (Nees) Lindau

Acanthaceae

Schinus lentiscifolius Marchand

Anacardiaceae

Schinus molle $\mathrm{L}$. Anacardiaceae

\footnotetext{
${ }^{12}$ Malvaceae, segundo Sobral \& Jarenkow (2006, p. 122).

${ }^{13}$ Machaonia brasiliensis (Hoffmans. ex Humb.) Cham. \& Schltdl., segundo Sobral \& Jarenkow (2006, p. 144).

${ }^{14}$ Miconia hyemalis A.St.-Hil. \& Naudin ex Naudin, segundo Sobral \& Jarenkow (2006, p. 123).

${ }^{15}$ Nectandra megapotamica (Spreng.) Mez, segundo Sobral \& Jarenkow (2006, p. 116).

${ }^{16}$ Ocotea pulchella (Nees) Mez, segundo Sobral \& Jarenkow (2006, p. 118).

${ }^{17}$ Quillaja brasiliensis (A.St.-Hil. \& Tul.) Mart., da família Quillajaceae, segundo Sobral \& Jarenkow (2006, p. 142).
} 
Scutia buxifolia Reissek

Rhamnaceae

Sebastiania brasiliensis Spreng.

Euphorbiaceae

Sebastiania commersoniana (Baill.) L.B.Sm. \& R.J.Downs

Euphorbiaceae

Senegalia tucumanensis (Griseb.) Seigler \& Ebinger

Fabaceae

Smallanthus connatus (Spreng.) H.Rob.

Asteraceae

Stenachaenium campestre Baker

Asteraceae

Strychnos brasiliensis Mart. ${ }^{18}$

Loganiaceae

Styrax leprosus Hook. \& Arn.

Styracaceae

Symplocos uniflora Benth. ${ }^{19}$

Symplocaceae

Terminalia australis Cambess.

Combretaceae

Tillandsia toropiensis Rauh

Bromeliaceae

Trema micrantha (L.) Blume

Ulmaceae $^{20}$

Trichilia elegans A.Juss.

Meliaceae

Trimezia spathata Baker

Iridaceae

Trithrinax brasiliensis Mart.

Arecaceae

Trixis pallens Less.

Asteraceae

Vitex megapotamica (Spreng.) Moldenke

Lamiaceae

Vriesea friburgensis Mez

Bromeliaceae

Vriesea platynema Gaudich.

Bromeliaceae

Zanthoxylum rhoifolium Lam.

Rutaceae

\section{REFERÊNCIAS BIBLIOGRÁFICAS}

ANDERSON, E.F. The cactus family. Portland: Timber Press, 2001. 776 p.

BOLDRINI, I.I. A flora dos campos do Rio Grande do Sul. In: PILLAR, V.P.; MÜLLER, S.C.; CASTILHOS, Z.M.S.; JACQUES, A.V.A. (eds.). Campos sulinos. Conservação e uso sustentável da biodiversidade. Brasília: Ministério do Meio Ambiente, Secretaria de Biodiversidade e Florestas, Departamento de Conservação da Biodiversidade, 2009. p. 63-77.

BÜNEKER, H.M.; PONTES, R.C.; SOARES, K.P.; WITECK-NETO, L.; LONGHI, S.J. Uma nova espécie reófita de Dyckia (Bromeliaceae, Pitcarnioideae) para a flora do Rio Grande do Sul, Brasil. Revista Brasileira de Biociências, Porto Alegre, v. 11, n. 3, p. 284-289, 2013.

DEBLE, L.P.; ALVES, F. da S. Herbertia amabilis Deble \& F.S. Alves (Iridaceae), a new species from Brazil. Candollea, Genève, n. 68, p., 133137, 2013.
FIGUEIREDO, M.C. dos S. Florística de mata ciliar em São Martinho da Serra, RS, Brasil. Santa Maria: Universidade Federal de Santa Maria, 2014. 64 f. Dissertação (Programa de PósGraduaçào em Agrobiologia).

FIGUEIREDO, M.C. dos S.; GRIGOLETTO, D.; BERTUZZI, T.; CANTO-DOROW, T. S. do; EISINGER, S.M. Ocorrência de Oxalis subvillosa Norlind (Oxalidaceae) no Rio Grande do Sul, Brasil. Iheringia, Ser. Bot., Porto Alegre, v. 68, n. 2, p. 285-288, 2013.

HOFACKER, A. Notokakteen: Von Acanthocephala bis Wigginsia. Deutsche Kakteen-Gesellschaft \& V. Adelsdorf, 2013. 144 p.

PROCHNOW, M. A importância das florestas do vale do rio Pelotas. In: PROCHNOW, M. (Org.). Barra Grande: a hidrelétrica que não viu a floresta. Rio Grande do Sul: Apremavi, 2005. p. 8-14.

RAUH, W. Bromelienstudien, Tillandsia toropiensis. Tropische und subtropische Pflanzenwelt, Mainz, n. 50, p. 10-13, 1984.

${ }^{18}$ Strychnos brasiliensis (Spreng.) Mart., segundo Sobral \& Jarenkow (2006, p. 120).

${ }^{19}$ Symplocos uniflora (Pohl) Benth., segundo Sobral \& Jarenkow (2006, p. 154).

${ }^{20}$ Cannabaceae, segundo Sobral \& Jarenkow (2006, p. 98). 
RITTER, F. Kakteen in Südamerika: Ergebnisse Meiner 20-jährigen Feldforschung. Spangenberg, 1979. v. 1. 378 p.

RUA, G.H.; VALLS, J.F.M. On the taxonomic status of the genus Thrasyopsis (Poaceae, Panicoideae, Paspaleae): new combinations in Paspalum. Phytotaxa, n. 73, p. 60-66, 2012.

SOARES, K.P.; LONGHI, S.J. Uma nova espécie de Butia (Becc.) Becc. (Arecaceae) para o Rio Grande do Sul, Brasil. Ciência Florestal, Santa Maria, v. 21, n. 2, p. 203-208, 2011.

SOARES, K.P.; LONGHI, S.J.; WITECK NETO, L.; ASSIS, L.C. de. Palmeiras (Arecaceae) no Rio Grande do Sul, Brasil. Rodriguésia, Rio de Janeiro, v. 65, n. 1, p. 113-139, 2014.

SOBRAL, M.; JARENKOW, J.A. (Orgs.). Flora arbórea e arborescente do Rio Grande do Sul, Brasil. São Carlos: RiMA : Novo Ambiente, 2006. $350 \mathrm{p}$

VALLS, J.F.M.; BOLDRINI, I.I.; LONGHIWAGNER, H.M.; MIOTTO, S.T.S. O patrimônio florístico dos campos: poten- cialidades de uso e a conservação de seus recursos genéticos. In: PILLAR, V.P.; MÜLLER, S.C.; CASTILHOS, Z.M.S.; JACQUES, A.V.A. (eds.). Campos sulinos: Conservação e uso sustentável da biodiversidade. Brasília: Ministério do Meio Ambiente, Secretaria de Biodiversidade e Florestas, Departamento de Conservação da Biodiversidade, 2009. p. 139-154.

WIESBAUEER, M.B. Biologia reprodutiva e diversidade genética de Dyckia distachya Hassler (Bromeliaceae) como subsídio para a conservação e reintrodução de populações extintas na natureza. Florianópolis: Universidade Federal de Santa Catarina, 2008. 95 p. Dissertação (Programa de Pós-Graduação em Recursos Genéticos Vegetais).

WIESBAUER, M.B.; HMELJEVSKI, K.V.; ZIMMERMANN, T.G.; REIS, M.S. dos; REIS, A.; SOUZA, S. L. de. Reintrodução de Dyckia distachya Hassler nas áreas de influência das hidrelétricas de Itá e Machadinho. UFSC: Recursos Genéticos Vegetais, 2009. 